\title{
Clinical Significance of Signet-Ring-Cell Colorectal Cancer as a Prognostic Factor
}

\author{
Sang-Oh Yun, Yong Beom Cho, Woo Yong Lee, Hee Cheol Kim, Seong Hyeon Yun, Yoon Ah Park, \\ Jung Wook Huh \\ Department of Surgery, Samsung Medical Center, Sungkyunkwan University School of Medicine, Seoul, Korea
}

Purpose: The aim of this study is to evaluate the prognosis for patients with a signet-ring-cell carcinoma (SRCC) who undergo curative surgery by comparing them to patients with an adenocarcinoma (ADC), excluding a mucinous ADC.

Methods: Between September 1994 and December 2013, 14,110 patients with colorectal cancer underwent surgery and among them, 12,631 patients were enrolled in this study. 71 patients with a SRCC and 12,570 patients with a ADC were identified. We analyzed the disease-free survival and the overall survival rates before and after a 1:2 propensity score matching and evaluated those rates after stage stratification.

Results: The median follow-up durations were 48.5 months for the SRC group and 48.6 months for the ADC group. The disease-free survival rates and the overall survival rates were significantly lower in the SRC group before and after propensity score matching $(\mathrm{P}<0.001)$. After stratification by stage, no differences were observed between the SRC and the ADC groups for the disease-free survival (DFS) and the overall survival (OS) rates for patients with cancer in its early stages $(\mathrm{P}=0.913$ and $\mathrm{P}=0.380$ for the $\mathrm{DFS}$ and the $\mathrm{OS}$, respectively, in stages 0 and $\mathrm{I}$, and $\mathrm{P}=0.223$ and $\mathrm{P}=0.991$ for the DFS and the OS, respectively, in stage II), but those rates were significantly lower in the SRC group for cancer in its later stages $(\mathrm{P}<0.001$, respectively in stages III and IV).

Conclusion: For cancer in advanced stages, patients with a resectable colorectal SRCC had a poorer prognosis after propensity score matching than those with an ADC did. Therefore, more intensive surveillance and closer observation should be offered to such patients.

Keywords: Signet-ring cell; Adenocarcinoma; Colorectum; Prognosis; Stage

\section{INTRODUCTION}

Recently, colorectal cancer (CRC) has become a worldwide health issue in both morbidity and mortality. In Western societies, CRC is the third most common cancer $[1,2]$, and in Asia, CRC morbidity is increasing $[3,4]$. CRC is a heterogeneous type of cancer, meaning that a variety of different histology types, including ade-

Received: September 5, 2017 - Accepted: September 29, 2017 Correspondence to: Yong Beom Cho, M.D.

Department of Surgery, Samsung Medical Center, Sungkyunkwan University School of Medicine, 81 Irwon-ro, Gangnam-gu, Seoul 06351, Korea

Tel: +82-2-3410-0217, Fax: +82-2-3410-6982,

E-mail:yongbeom.cho@samsung.com

(C) 2017 The Korean Society of Coloproctology

This is an open-access article distributed under the terms of the Creative Commons Attribution NonCommercial License (http://creativecommons.org/licenses/by-nc/4.0) which permits unrestricted noncommercial use, distribution, and reproduction in any medium, provided the original work is properly cited. nocarcinomas (ADCs), adenosquamous carcinomas, spindle cell carcinomas, squamous cell carcinomas, and undifferentiated carcinomas, are possible [5]. According to its histologic type, CRC has different clinical features; thus, identifying the characteristics of each CRC subtype is an important step in managing the treatment of patients with CRC appropriately.

Among these pathologic subtypes, signet-ring-cell carcinomas (SRCCs) of the colon and of the rectum are rare histologic subtypes of colorectal ADCs and account for only approximately $0.5 \%-1 \%$ and $15 \%-20 \%$ of all ADCs, respectively [6]. By definition, a $50 \%$ or greater signet-ring-cell component is required for a colorectal carcinoma to be designated as a signet-ring-cell colorectal carcinoma $[7,8]$. Because many patients with a SRCC are diagnosed at more advanced stages and in an unresectable state, the prognosis for such a patient is generally poorer than that for a patient with a colorectal non-mucinous ADC [9-12]. According to previous studies, a specific histological type of colorec- 
tal carcinoma such as a SRCC has a poorer prognosis [13-15], but the results in previous studies cannot be readily and widely accepted because of their limitations, such as their small sample size and the lack of propensity matching in the study's design.

Until now, not many studies have used propensity score matching to determine the prognostic significance of a SRCC. In this research, we attempt to identify whether or not the poor prognosis associated with patients with SRCCs is due to the histologic type being a signet-ring-cell type itself or is a secondary outcome due to the cancer's advanced stage. A further aim of this study is to evaluate the relationship between the clinicopathologic features of SRCCs and the prognosis for patients with a SRCC and to compare any identified relationship to the corresponding known relationships for patients with colorectal ADCs.

\section{METHODS}

\section{Patients}

The study was approved by the Institutional Review Board at Samsung Medical Center (201311008), and all patients provided written informed consent prior to study enrollment. The records from 14,110 patients with CRC who were treated at Samsung Medical Center, a tertiary referral center in Korea, and who underwent surgical resection from September 1994 to December 2013 were retrospectively reviewed. All patients had a histologically confirmed primary SRCC or ADC of the colon and rectum; patients were excluded if they had recurrent disease, synchronous malignancies, or a primary mucinous carcinoma. After such patients had been excluded, 12,641 patients were enrolled.

Insufficient data were re-evaluated using electronic medical charts. The preoperative clinical evaluation included physical examination, colonoscopy, abdominopelvic computed tomography (CT), chest radiography or CT, complete blood cell count, liver function test, and carcinoembryonic antigen (CEA) level. Depending on the disease's extent, rectal or liver magnetic resonance imaging and CT combined with positron emission tomography were also performed. The location of the tumor was defined as the distance between the anal verge (AV) and the tumor's caudal margin. This was measured via digital examination or colonoscopy. After surgery, patients continued to be managed during a follow-up period according to the National Comprehensive Cancer Network postoperative surveillance protocol.

\section{Histologic assessment}

Histologic sections of the tumors were examined, and the following features were recorded: depth of tumor invasion, vascular invasion, lymph-node metastasis, the percentage of the signet-ringcell component of the tumor cells, and the percentage of extracellular mucin content in the tumor volume. The depth of tumor invasion, lymph-node metastasis, and clinical information were used to assign a tumor stage by using the TNM classification as described in the American Joint Committee on Cancer, AJCC

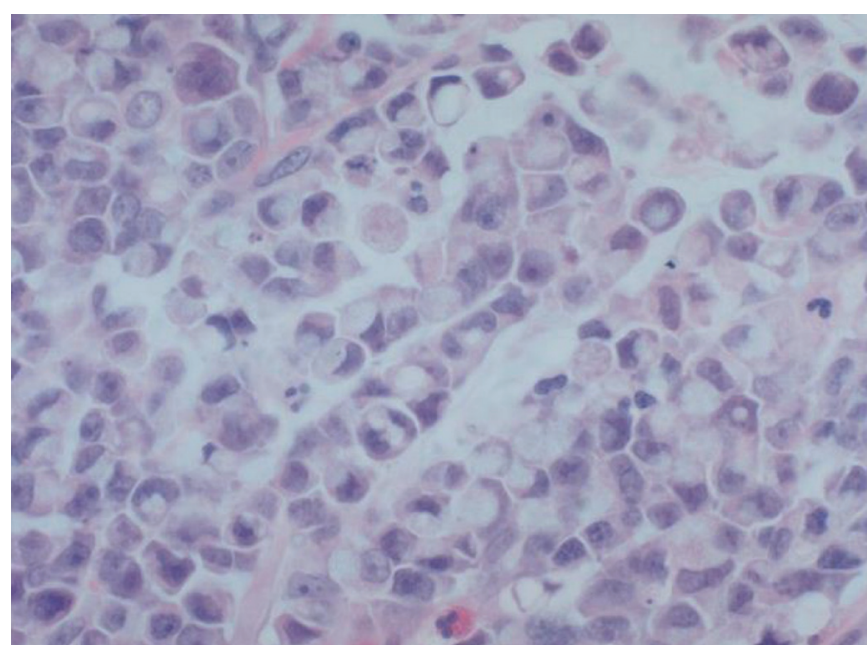

Fig. 1. Primary signet-ring-cell carcinoma deletion of the colon (H\&E, $\times 400)$.

\section{Cancer Staging Manual.}

The following criteria were used for the diagnosis of a SRCC: $50 \%$ of tumor cells with prominent intracytoplasmic mucin, presence of signet-ring cells as the dominant (50\%) malignant cell type, and the formation of immature glands (Fig. 1). ADC was defined as lesions exhibiting glandular structures in 5\%-50\% of the tumor. All cases were reviewed by an expert pathologist who is an expert in the field.

\section{Statistical analysis}

The overall survival (OS) and the disease-free survival (DFS) rates were estimated by using the Kaplan-Meier method, and the groups were compared using the log-rank test. A comparison between means was performed via the Student t-test, and proportions were compared by using either the chi-square test or Fisher exact test, which was for smaller numbers. Differences were considered statistically significant at $\mathrm{P}<0.05$.

Propensity score matching was performed in our study to stratify adjustments for differences in baseline characteristics among signet-ring-cell and ADC colon cancer variants. The clinicopathological characteristics that can influence OS and DFS rates were stringently adjusted using propensity score matching: age ( $<65$ or $\geq 65$ years), sex, preoperative CEA ( $<5$ or $\geq 5 \mathrm{ng} / \mathrm{mL}$ ), location (colon or rectum), surgical approach (open or laparoscopic), stage, lymphatic invasion, vascular invasion, perineural invasion, and adjuvant treatment. After propensity score matching, a logistic regression analysis was performed to determine the differences in DFS and OS for SRC vs. ADC.

\section{RESULTS}

\section{Patient characteristics}

The data from the 14,110 patients who had undergone surgical 
Table 1. Patients' characteristics before matching

\begin{tabular}{|c|c|c|c|}
\hline Variable & $\begin{array}{c}\text { SRCC } \\
(n=71)\end{array}$ & $\begin{array}{c}\text { ADC } \\
(n=12,570)\end{array}$ & P-value \\
\hline Age (yr) & & & 0.066 \\
\hline$<65$ & $53(74.6)$ & $8,067(64.2)$ & \\
\hline$\geq 65$ & $18(25.4)$ & $4,503(35.8)$ & \\
\hline Sex & & & 0.468 \\
\hline Male & $46(64.8)$ & $7,614(60.6)$ & \\
\hline Female & 25 (35.2) & 4,956 (39.4) & \\
\hline Preoperative CEA level (ng/mL) & & & 0.317 \\
\hline$<5$ & $48(67.6)$ & 9,209 (73.3) & \\
\hline$\geq 5$ & $14(19.7)$ & $2,359(18.8)$ & \\
\hline Unknown & $9(12.7)$ & $1,002(8.0)$ & \\
\hline Location of tumor & & & 0.711 \\
\hline Colon & $42(59.2)$ & $7,671(61.0)$ & \\
\hline Rectum & $29(40.8)$ & $4,899(39.0)$ & \\
\hline Approach of operation & & & 0.747 \\
\hline Open & $39(54.9)$ & $7,213(57.4)$ & \\
\hline Laparoscopic & $32(45.1)$ & $5,357(42.6)$ & \\
\hline Stage & & & $<0.001$ \\
\hline 0 & $3(4.2)$ & $206(1.6)$ & \\
\hline । & $8(11.3)$ & $3,038(24.2)$ & \\
\hline$\|$ & $11(15.5)$ & $3,915(31.1)$ & \\
\hline III & $33(46.5)$ & 4,676 (37.2) & \\
\hline IV & $16(22.5)$ & $735(5.8)$ & \\
\hline Lymphatic invasion & & & $<0.001$ \\
\hline Yes & $43(60.6)$ & $3,119(24.8)$ & \\
\hline No & $18(25.4)$ & 6,951 (55.3) & \\
\hline Unknown & $10(14.1)$ & 2,500 (19.9) & \\
\hline Vascular invasion & & & $<0.001$ \\
\hline Yes & $26(36.6)$ & $1,681(13.4)$ & \\
\hline No & $30(42.3)$ & $7,717(61.4)$ & \\
\hline Unknown & $15(21.1)$ & $3,172(25.2)$ & \\
\hline Perineural invasion & & & $<0.001$ \\
\hline Yes & $16(22.5)$ & $1,557(12.4)$ & \\
\hline No & $40(56.3)$ & $7,298(58.1)$ & \\
\hline Unknown & $15(21.1)$ & 3,715 (29.6) & \\
\hline Adjuvant treatment & & & $<0.001$ \\
\hline Yes & $55(77.5)$ & $6,882(54.7)$ & \\
\hline No & $16(22.5)$ & $3,724(29.6)$ & \\
\hline Unknown & $0(0)$ & 2,331 (18.5) & \\
\hline
\end{tabular}

Values are presented as number (\%).

SRCC, signet-ring-cell carcinoma; ADC, adenocarcinoma; CEA, carcinoembryonic antigen. resection of a CRC between September 1994 and December 2013 were reviewed. We excluded patients with recurrent disease, synchronous malignancies, or a primary mucinous carcinoma, leaving 12,631, of whom 71 patients with a SRCC were identified. Clinicopathologic data, including age, sex, preoperative CEA level, tumor location, surgical approach, lymphatic invasion, vascular invasion, perineural invasion, and adjuvant treatment, were retrospectively analyzed. As shown in Table 1, except for age, sex, preoperative CEA level, location of the tumor, and surgical approach, variables for the SRCC and the ADC groups were different. Features of advanced disease, including lymphovascular invasion, and perineural invasion, and previous adjuvant treatment were more common in the SRCC group than they were in the ADC group.

\section{Survival outcomes according to histologic subtype}

Propensity score matching (1:2) was performed to reduce confounding bias. Additionally, matching between SRCC and ADC yielded 71 matched pairs, and between these pairs, no significant differences in clinic-pathologic characteristics between the two variants were found (Fig. 2, Table 2).

As shown in Fig. 3, which compares the survival outcomes for the ADC vs. the SRC group, OS rates and DFS rates were significantly lower for the SRCC group $(\mathrm{P}<0.001)$. The 5 -year survival rate for the SRCC group was $56.2 \%$ while that for the ADC group was $84.9 \%(\mathrm{P}<0.001)$, and the 5 -year disease-free survival rate for the SRCC group was $41.3 \%$ while that for the ADC group was $68.9 \%(\mathrm{P}=0.001)$.

In the univariate analysis, rectum $(\mathrm{P}=0.001)$, SRCC $(\mathrm{P}=0.001)$,

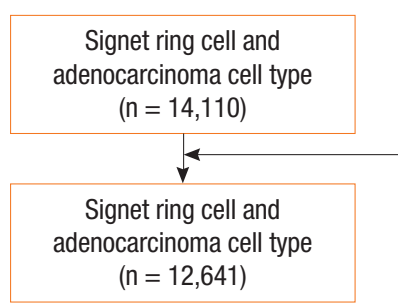

Exclusion criteria
Recurrent disease,
Synchronous malignancy,
Primary mucinous carcinoma,
Hereditary familial cancer,
Palliative purpose

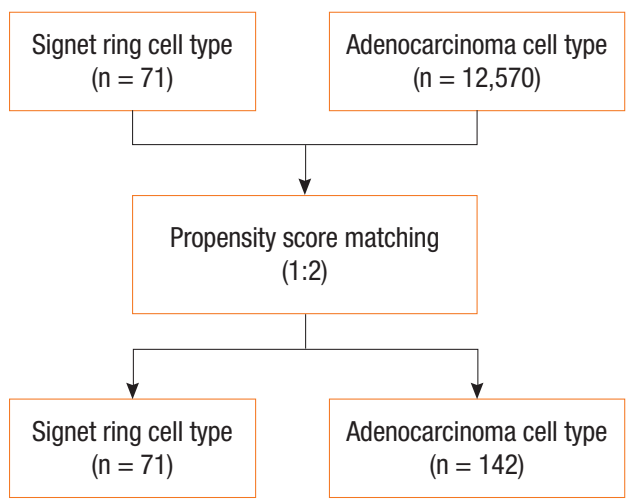

Fig. 2. Matching table. 
Table 2. Patients' characteristics after matching

\begin{tabular}{|c|c|c|c|}
\hline Variable & $\begin{array}{c}\text { SRCC } \\
(n=71)\end{array}$ & $\begin{array}{c}\text { ADC } \\
(n=142)\end{array}$ & P-value \\
\hline Age (yr) & & & 0.394 \\
\hline$<65$ & $53(74.6)$ & $98(69.0)$ & \\
\hline$\geq 65$ & $18(25.4)$ & $44(31.0)$ & \\
\hline Sex & & & 0.322 \\
\hline Male & $46(64.8)$ & $82(57.7)$ & \\
\hline Female & 25 (35.2) & 60 (42.3) & \\
\hline Preoperative CEA level (ng/mL) & & & 0.397 \\
\hline$<5$ & $48(67.6)$ & $102(71.8)$ & \\
\hline$\geq 5$ & $14(19.7)$ & $30(21.1)$ & \\
\hline Unknown & $9(12.7)$ & $10(7.0)$ & \\
\hline Location of tumor & & & 0.843 \\
\hline Colon & $42(59.2)$ & $86(60.6)$ & \\
\hline Rectum & $29(40.8)$ & $56(39.4)$ & \\
\hline Approach of operation & & & 0.134 \\
\hline Open & $39(54.9)$ & $93(65.5)$ & \\
\hline Laparoscopic & $32(45.1)$ & $49(34.5)$ & \\
\hline Stage & & & 0.413 \\
\hline 0 & $3(4.2)$ & $1(0.7)$ & \\
\hline I & $8(11.3)$ & $12(8.5)$ & \\
\hline$\|$ & $11(15.5)$ & 27 (19.0) & \\
\hline III & $33(46.5)$ & $67(47.2)$ & \\
\hline IV & $16(22.5)$ & $35(24.6)$ & \\
\hline Lymphatic invasion & & & 0.804 \\
\hline Yes & $26(36.6)$ & $46(32.4)$ & \\
\hline No & $30(42.3)$ & $66(46.5)$ & \\
\hline Unknown & 15 (21.1) & 30 (21.1) & \\
\hline Vascular invasion & & & 0.645 \\
\hline Yes & $26(36.6)$ & 46 (32.4) & \\
\hline No & 30 (42.3) & 66 (46.5) & \\
\hline Unknown & 15 (21.1) & 30 (21.1) & \\
\hline Perineural invasion & & & 0.592 \\
\hline Yes & 16 (22.5) & $24(16.9)$ & \\
\hline No & 40 (56.3) & $88(62.0)$ & \\
\hline Unknown & 15 (21.1) & 30 (21.1) & \\
\hline Adjuvant treatment & & & 0.072 \\
\hline Yes & 55 (77.5) & $103(72.5)$ & \\
\hline No & 18 (22.5) & 29 (20.4) & \\
\hline Unknown & $0(0)$ & $10(7.0)$ & \\
\hline
\end{tabular}

Values are presented as number (\%).

SRCC, signet-ring-cell carcinoma; ADC, adenocarcinoma; CEA, carcinoembryonic antigen. advanced stage (III, IV) $(\mathrm{P}<0.001)$, lymphatic invasion $(\mathrm{P}=$ $0.001)$, perineural invasion $(\mathrm{P}=0.032)$, and vascular invasion ( $\mathrm{P}$ $=0.002)$ showed an unfavorable influence on DFS, and high CEA level $(\mathrm{P}=0.008)$, SRCC $(\mathrm{P}<0.001)$, advanced stage $(\mathrm{P}<0.001)$, and lymphatic invasion $(\mathrm{P}=0.001)$ showed an unfavorable influence on OS. After the multivariate analysis for prognostic factors in matching patients, signet-ring-cell type (hazard ratio [HR], $1.848 ; \mathrm{P}<0.012 ; \mathrm{HR}, 2.536 ; \mathrm{P}=0.001$, respectively), rectum (HR, $2.280 ; \mathrm{P}=0.001 ; \mathrm{HR}, 1.746 ; \mathrm{P}=0.038$, respectively), and lymphatic invasion (HR, 2.547; $\mathrm{P}=0.006 ; \mathrm{HR}, 2.864 ; \mathrm{P}=0.007$, respectively) were the independent prognostic factor for both DFS and $O S$ rates (Table 3 ).

In our study, significant differences in the DFS and the OS rates between the SRCC and the ADC groups were found before propensity score matching $(\mathrm{P}<0.001)$, but those rates were significantly different between those groups $(\mathrm{P}=0.001, \mathrm{P}<0.001$, respectively) after propensity score matching (Fig. 3). However, during the first 12 months after surgery, no large differences in DFS were observed after propensity score matching.

\section{Stage-stratified survival outcomes of SRC}

We performed a subgroup analysis that was stratified by stage to evaluate the DFS and the OS rates more precisely. No differences in the DFS and the OS rates were observed at early stages $(\mathrm{P}=$ 0.913 and $\mathrm{P}=0.380$ for DFS and OS, respectively, in stages 0 and $\mathrm{I}$, and $\mathrm{P}=0.223$ and $\mathrm{P}=0.991$ for DFS and OS, respectively, in stage II), but for late stages (III and IV), those rates were found to be significantly lower for the SRCC group $(\mathrm{P}<0.001$, respectively) (Fig. 4).

\section{DISCUSSION}

A SRCC of the colorectum was first reported in 1951 [16]. It is a rare and distinctive type of cancer [6], and its prognosis is poorer than the prognoses for other types. It usually presents at more advanced stages because its clinical symptoms develop late [9]. Bonello et al. [17] reported that this delay in diagnosis was due to its rarity and intramucosal tumor spread with relative sparing of the mucosa.

In some studies [18, 19], researchers used univariate analyses to report that a lower TNM stage and the absence of lymphovascular invasion had favorable effects on the survival rates of patients with a SRCC. Decreased invasion depth and no lymph-node metastasis also had favorable effects on survival in patients with a SRCC and patients with an ADC. Moreover, Sung et al. [14] reported that the absence of lymphatic invasion had a favorable outcome on OS compared to previous studies. In other previous studies, mucinous histologic type was an independent poor prognostic factor in some studies [20,21], but not in others [22-24]. Wu et al. [22] suggested that the different DFS and OS rates could be associated with differences in the stage upon presentation rather than the cancer's pathologic subtype. 

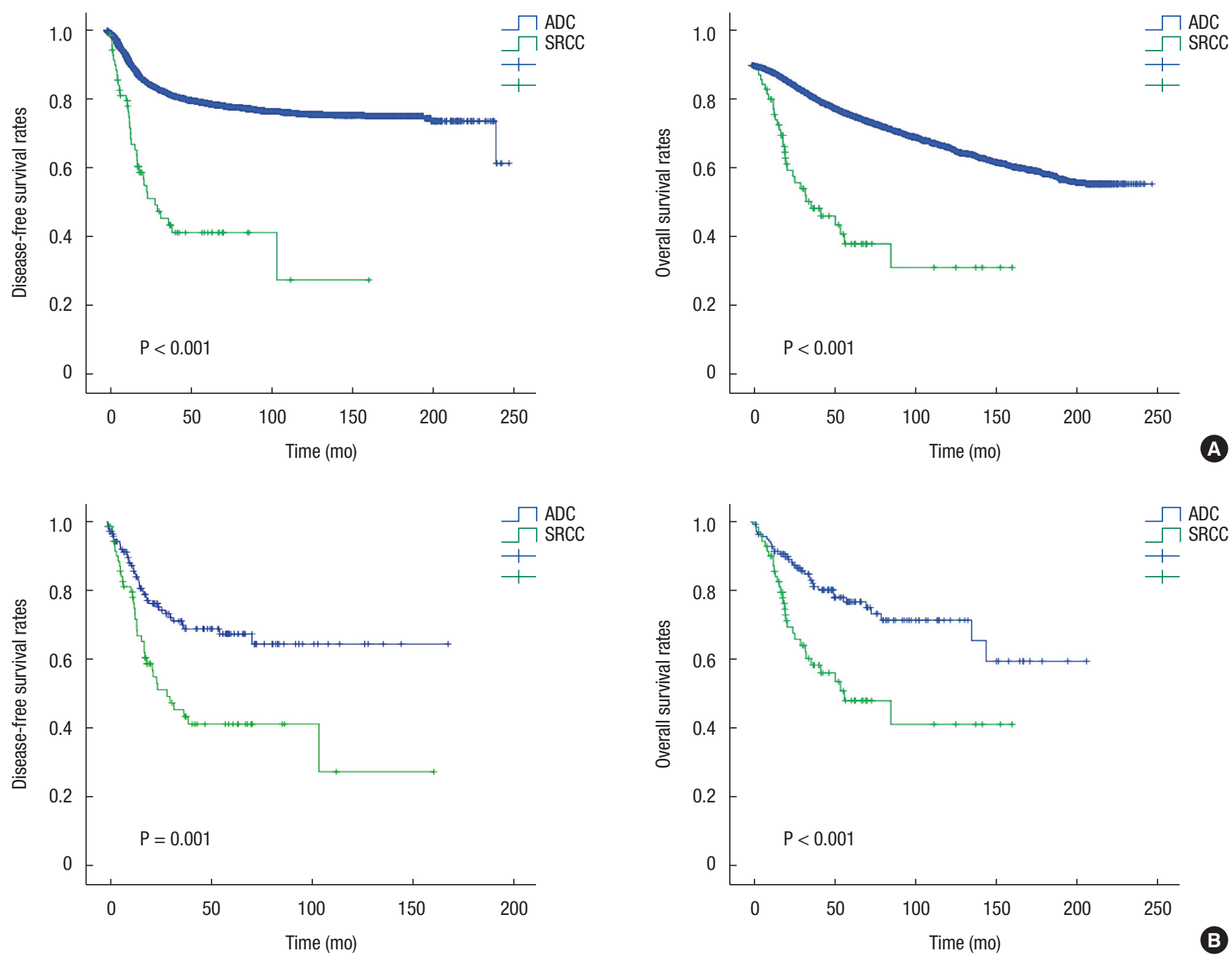

Fig. 3. Survival outcomes for patients with an adenocarcinoma (ADC) vs. those with a signet-ring-cell carcinoma (SRCC): before (A) and after matching (B).

Table 3. Multivariate analysis for prognostic factors in all patients after propensity score matching

\begin{tabular}{|c|c|c|c|c|}
\hline \multirow{2}{*}{ Variable } & \multicolumn{2}{|c|}{ Disease-free survival } & \multicolumn{2}{|c|}{ Overall survival } \\
\hline & P-value & $\mathrm{HR}(95 \% \mathrm{Cl})$ & P-value & $\mathrm{HR}(95 \% \mathrm{Cl})$ \\
\hline Cell type, SRCC vs. ADC & 0.012 & $1.848(1.143-2.990)$ & 0.001 & $2.536(1.448-4.323)$ \\
\hline Age (yr), $\geq 65$ vs. $<65$ & 0.927 & $0.974(0.551-1.720)$ & 0.242 & $1.417(0.790-2.542)$ \\
\hline Sex, female vs. male & 0.777 & $0.927(0.551-1.561)$ & 0.917 & $1.031(0.583-1.821)$ \\
\hline Preoperative CEA level (ng/mL), $\geq 5$ vs. $<5$ & 0.118 & $1.571(0.892-2.768)$ & 0.009 & $2.102(1.206-3.663)$ \\
\hline Location of tumor, rectum vs. colon & 0.001 & $2.280(1.412-3.683)$ & 0.038 & $1.746(1.031-2.954)$ \\
\hline Approach of operation, laparoscopic vs. open & 0.796 & $0.931(0.544-1.594)$ & 0.289 & $0.704(0.368-1.347)$ \\
\hline Stage, III-IV vs. 0-I & $<0.001$ & $4.479(2.152-9.325)$ & $<0.001$ & $3.773(1.795-7.929)$ \\
\hline Lymphatic invasion, yes vs. no & 0.006 & $2.547(1.306-4.966)$ & 0.007 & $2.864(1.332-6.155)$ \\
\hline Vascular invasion, yes vs. no & 0.039 & $1.738(1.029-2.935)$ & 0.429 & $1.274(0.699-2.323)$ \\
\hline Perineural invasion, yes vs. no & 0.202 & $1.444(0.821-2.537)$ & 0.449 & $0.740(0.340-1.613)$ \\
\hline Adjuvant treatment, yes vs. no & 0.072 & $1.899(0.994-3.817)$ & 0.335 & 1.395 (0.709-2.743) \\
\hline
\end{tabular}

$\mathrm{HR}$, hazard ratio; $\mathrm{Cl}$, confidence interval; SRCC, signet-ring-cell carcinoma; $\mathrm{ADC}$, adenocarcinoma; CEA, carcinoembryonic antigen. 

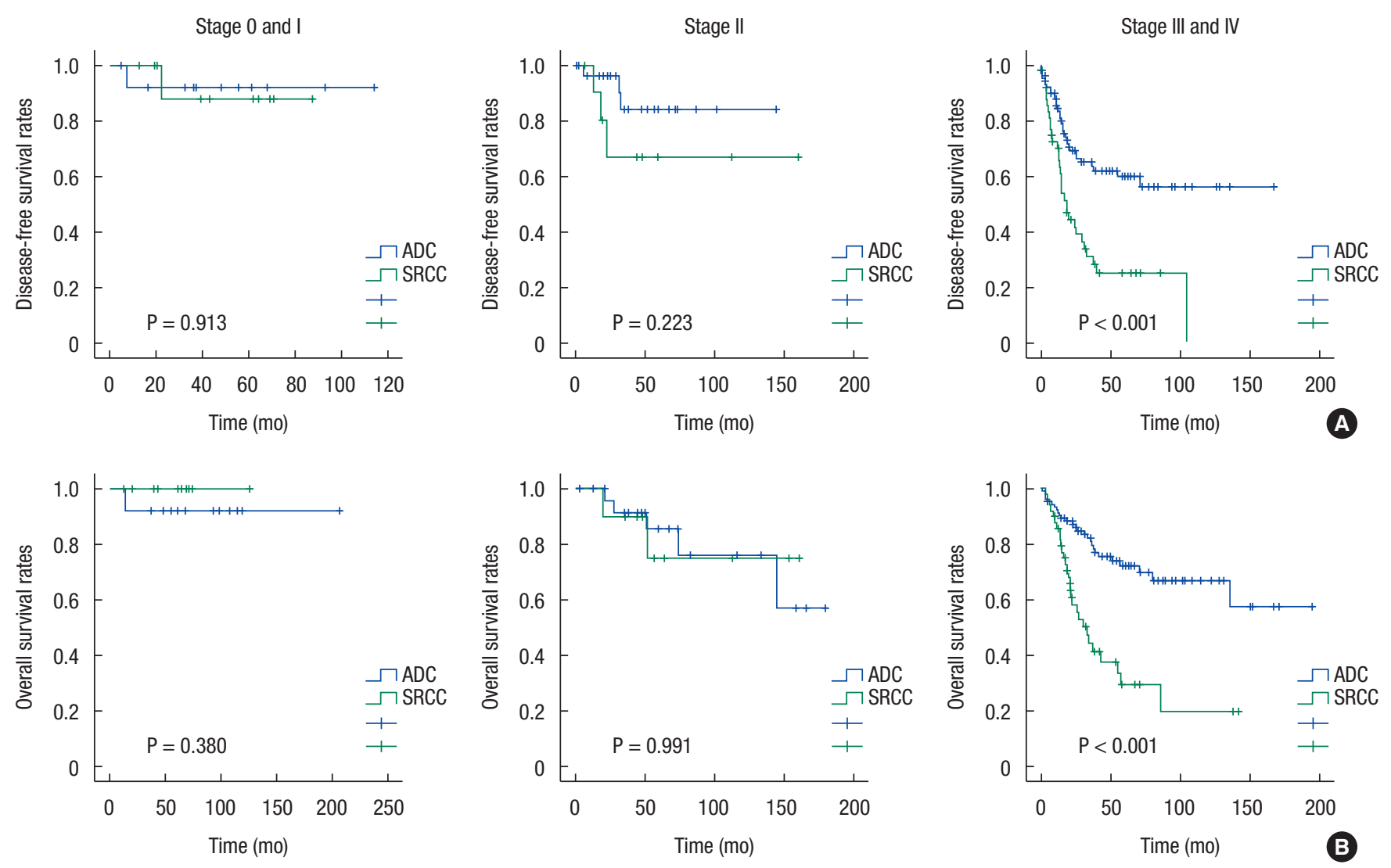

Fig. 4. Survival outcomes for patients with an adenocarcinoma (ADC) vs. those with a signet-ring-cell carcinoma (SRCC) according to stage in matched patients: disease-free survival (A) and overall survival (B).

In our research, we found that in patients with a resectable, nonhereditary, primary colorectal SRCC, the DFS and the OS rates were significantly lower in the SRCC group compared to the $\mathrm{ADC}$ group before propensity score matching, and the results were the same after propensity score matching. In a subgroup analysis stratified by stage after propensity score matching, the SRCC histologic type could be regarded as an independent poor prognostic factor when the cancer was in an advanced stage although no significant differences in DFS and OS were found between the SRCC and the ADC groups when the cancer was in an early stage. We might explain the poor prognosis for patients with a SRCC by the aggressiveness of its infiltrating growth because of the higher rate of lymphovascular invasion; in addition, slow infiltration without penetrating the mucosa layer could be the reason for its late diagnosis, meaning that SRCC could be diagnosed at a more advanced stage [5, 8, 10-12].

Our study has several limitations. First, we collected patient data from a single comprehensive cancer center. Considering the Korean medical environment, patients with a higher social economic status and a more advanced disease usually go to tertiary medical centers. This means that selection bias must be considered and that our results may not be generalizable to all patients with sig- net-ring-cell colon cancer. Second, this is not a prospective cohort; therefore, the treatment strategy was selected according to the surgeon's preference and choice and so was not controlled. Third, its statistical power is limited due to the rarity of SRCC. However, the number of SRCC patients was maintained as 71 before and after propensity score matching; thus, we could maintain statistical power quiet well. We collected patient data from a single cancer center, but we could collect relatively many SRCC patient data and exclude the surgical technique's influence on DFS and OS because the Samsung Medical Center is a comprehensive cancer center.

In conclusion, SRCC is an uncommon and rare subtype of CRC that shows poor OS and DFS rates compared to other histologic types such as a classical ADC. In many other studies, SRCC is frequently diagnosed at a more advanced stage and with more aggressive pathologic features, such as lymphovascular or neural invasion, which eventually translates to poor survival $[8,22]$; however, in our study, we could regard SRCC as the single prognostic factor of CRC. Therefore, more intensive surveillance and closer follow-up should be afforded to patients with SRCC, despite the condition's relatively rarity. 


\section{CONFLICT OF INTEREST}

No potential conflict of interest relevant to this article was reported.

\section{REFERENCES}

1. Siegel R, Naishadham D, Jemal A. Cancer statistics, 2013. CA Cancer J Clin 2013;63:11-30.

2. Connelly JH, Robey-Cafferty SS, el-Naggar AK, Cleary KR. Exophytic signet-ring cell carcinoma of the colorectum. Arch Pathol Lab Med 1991;115:134-6.

3. Sung JJ, Lau JY, Goh KL, Leung WK; Asia Pacific Working Group on Colorectal Cancer. Increasing incidence of colorectal cancer in Asia: implications for screening. Lancet Oncol 2005;6:871-6.

4. Byeon JS, Yang SK, Kim TI, Kim WH, Lau JY, Leung WK, et al. Colorectal neoplasm in asymptomatic Asians: a prospective multinational multicenter colonoscopy survey. Gastrointest Endosc 2007;65:1015-22.

5. Nitsche U, Zimmermann A, Späth C, Müller T, Maak M, Schuster $\mathrm{T}$, et al. Mucinous and signet-ring cell colorectal cancers differ from classical adenocarcinomas in tumor biology and prognosis. Ann Surg 2013;258:775-82.

6. Almagro UA. Primary signet-ring carcinoma of the colon. Cancer 1983;52:1453-7.

7. Ogino S, Brahmandam M, Cantor M, Namgyal C, Kawasaki T, Kirkner G, et al. Distinct molecular features of colorectal carcinoma with signet ring cell component and colorectal carcinoma with mucinous component. Mod Pathol 2006;19:59-68.

8. Lee WS, Chun HK, Lee WY, Yun SH, Cho YB, Yun HR, et al. Treatment outcomes in patients with signet ring cell carcinoma of the colorectum. Am J Surg 2007;194:294-8.

9. Kim JH, Park SJ, Park MI, Moon W, Kim SE. Early-stage primary signet ring cell carcinoma of the colon. World J Gastroenterol 2013;19:3895-8.

10. Tung SY, Wu CS, Chen PC. Primary signet ring cell carcinoma of colorectum: an age- and sex-matched controlled study. Am J Gastroenterol 1996;91:2195-9.

11. Messerini L, Palomba A, Zampi G. Primary signet-ring cell carcinoma of the colon and rectum. Dis Colon Rectum 1995;38:118992.
12. Anthony T, George R, Rodriguez-Bigas M, Petrelli NJ. Primary signet-ring cell carcinoma of the colon and rectum. Ann Surg Oncol 1996;3:344-8.

13. Vallam KC, Desouza A, Bal M, Patil P, Engineer R, Saklani A. Adenocarcinoma of the rectum - a composite of three different subtypes with varying outcomes? Clin Colorectal Cancer 2016;15:e4752 .

14. Sung CO, Seo JW, Kim KM, Do IG, Kim SW, Park CK. Clinical significance of signet-ring cells in colorectal mucinous adenocarcinoma. Mod Pathol 2008;21:1533-41.

15. Chew MH, Yeo SA, Ng ZP, Lim KH, Koh PK, Ng KH, et al. Critical analysis of mucin and signet ring cell as prognostic factors in an Asian population of 2,764 sporadic colorectal cancers. Int J Colorectal Dis 2010;25:1221-9.

16. Laufman H, Saphir O. Primary linitis plastica type of carcinoma of the colon. AMA Arch Surg 1951;62:79-91.

17. Bonello JC, Quan SH, Sternberg SS. Primary linitis plastica of the rectum. Dis Colon Rectum 1980;23:337-42U.

18. Park SY, Lee HS, Choe G, Chung JH, Kim WH. Clinicopathological characteristics, microsatellite instability, and expression of mucin core proteins and p53 in colorectal mucinous adenocarcinomas in relation to location. Virchows Arch 2006;449:40-7.

19. Kakar S, Aksoy S, Burgart LJ, Smyrk TC. Mucinous carcinoma of the colon: correlation of loss of mismatch repair enzymes with clinicopathologic features and survival. Mod Pathol 2004;17:696700 .

20. Consorti F, Lorenzotti A, Midiri G, Di Paola M. Prognostic significance of mucinous carcinoma of colon and rectum: a prospective case-control study. J Surg Oncol 2000;73:70-4.

21. Kanemitsu Y, Kato T, Hirai T, Yasui K, Morimoto T, Shimizu Y, et al. Survival after curative resection for mucinous adenocarcinoma of the colorectum. Dis Colon Rectum 2003;46:160-7.

22. Wu CS, Tung SY, Chen PC, Kuo YC. Clinicopathological study of colorectal mucinous carcinoma in Taiwan: a multivariate analysis. J Gastroenterol Hepatol 1996;11:77-81.

23. Kang H, O'Connell JB, Maggard MA, Sack J, Ko CY. A 10-year outcomes evaluation of mucinous and signet-ring cell carcinoma of the colon and rectum. Dis Colon Rectum 2005;48:1161-8.

24. Halvorsen TB, Seim E. Influence of mucinous components on survival in colorectal adenocarcinomas: a multivariate analysis. J Clin Pathol 1988;41:1068-72. 